\title{
Ecological control of Triatoma dimidiata (Latreille, 1811): five years after a Costa Rican pilot project
}

\author{
Rodrigo Zeledón/ ${ }^{+}$, Julio C Rojas, Andrea Urbina, Marlen Cordero, Sue H Gamboa, \\ Elias S Lorosa', Sergio Alfaro \\ Laboratorio de Zoonosis, Escuela de Medicina Veterinaria, Facultad de Ciencias de la Salud, Universidad Nacional, Campus Benjamín \\ Nuñes, Heredia, Costa Rica ${ }^{1}$ Laboratorio Nacional e Internacional de Referência em Taxonomia de Triatomineos, \\ Instituto Oswaldo Cruz-Fiocruz, Rio de Janeiro, RJ, Brasil
}

An ecological pilot project for the control of Triatoma dimidiata allowed a new evaluation four and five years after environmental modifications in the peridomestic areas of 20 households. It was verified that the two groups of houses, 10 case-houses and 10 control-houses, were free of insects after those periods of time. In the first group, the owners started a chicken coop in the backyard and a colony of bugs was found there without infesting the house. In the second group, the inhabitants of one house once again facilitated the conditions for the bugs to thrive in the same store room, reaffirming that man-made ecotopes facilitates colonization. This ecological control method was revealed to be reliable and sustainable and it is recommended to be applied to those situations where the vectors of Chagas disease can colonize houses and are frequent in wild ecotopes.

Key words: Triatoma dimidiata - ecological control - Costa Rica

In Central America, two main domestic vectors of Chagas disease are well known. One of them, Rhodnius prolixus, was accidentally introduced in the region around 1912-1913, originally from Venezuela (Zeledón 2004). This fact makes the species strictly domestic in the Isthmus and vulnerable to total elimination from the infested areas by insecticide spraying. Thanks to the Central American Initiative for Chagas Disease Control, an effort by the Ministries of Health, launched in 1997 in Honduras, at least one country, El Salvador, has reported the species absent at present. Guatemala is in the process of confirming the eradication of this vector from its territory; in Honduras, small foci remain in only 15 localities of two departaments out of 184 previously infested departments; and in Nicaragua, it is still found in four foci of two departments near the Honduran border, after its elimination from 49 originally infested localities (OPS 2008, F Marín, unpublished observations).

The second vector, Triatoma dimidiata, is a native domestic and peridomestic species, very frequent in sylvan ecotopes, producing smaller colonies in houses and with a lower vector capacity than $R$. prolixus (Zeledón et al. 2001, Zeledón 2004). These facts offer some difficulties for the control of the species and there is evidence indicating that the chemical spraying by itself is not enough for combating this species (reviewed by Zeledón \& Rojas 2006). In fact, the Central American Initiative, among its objectives, has stated the need for the development of

Financial support: FORINVES, CONICIT (partially)

+ Corresponding author: rodrigozeledon@ice.co.cr

Received 11 June 2008

Accepted 25 August 2008 effective and innovative methods "for the control of $T$. dimidiata at the domiciliary and peridomiciliary levels" (OPS 2002, Ponce 2007).

During 2002 and 2003, we carried out a pilot control project aimed at making changes in a group of $T$. dimidiata infested houses, by environmentally managing what we considered to be man-made ecotopes for thriving bugs, in order to alter the entire biocenoses of each particular place (Zeledón \& Rojas 2006). The project was performed in an area of Aserrí County, $20 \mathrm{~km}$ southwest of San José, the capital of Costa Rica. A total of 20 infested houses were chosen and divided into two similar groups, 10 case-houses and 10 control-houses. In the case-houses, all sort of old and disordered objects were removed from the peridomestic areas where the insect colonies were concentrated. Only in two houses (one of each group) mild indoor infestations were detected, which disappeared during the time of the interventions. By using environmental modifications, we intended to demonstrate that it is possible to achieve the complete elimination of $T$. dimidiata by this "ecological control method", as we called it, or at least to produce a marked decrease in colonies by making life difficult for insects already thriving there or for adventitious visiting adult bugs, which were common in the surroundings, attempting to colonize peridomestic areas.

Samples of insects were taken from the 20 houses at different intervals, following a standardized protocol, for up to 13.5 months. It was observed at that time, that control-houses had a greater proportion of insects, except at the start of the study, and that the differences increased with time with a tendency of the case-house to lose infestation. At the end of the period, practically all modified houses were free of insects whereas in the control houses, six of the original ones (in at least three houses, the inhabitants decided to make the environmental modifications by themselves) maintained their insect 
populations or they increased to a significant level. The sampling of the two groups of houses, during equal periods of time, as established by the man/hour method, at the beginning and at the end of the experiment, showed means of 10.6 and 0.4 insects per house in case-houses, and 9.6 and 13.0 insects per house in the controls. All the remaining control-houses were finally submitted to the same treatment as the case-houses, at the end of the experiment (Zeledon \& Rojas 2006) with an accent.

We concluded that this ecological control method was efficient in eliminating the bugs, at least temporarily, and in making it difficult for newly arriving bugs, or for young nymphs or those born from remaining eggs, to start new colonies.

More recently, we decided to make a follow up to the experiment by reexamining both groups of houses, after five (case-houses) and four (control-houses) years of the interventions. The method used for searching of the 20 houses was the same as previously practiced and a person, who participated in the previous search, was in charge of the new task.

Of the 10 case-houses, eight maintained the modifications made by us and two were torn down and substituted by new constructions. The eight houses were all negative for bugs, but in one of them (house 37) the owners decided, about four years ago, to use a cellar located in the back yard, about $4 \mathrm{~m}$ from the house, as a store room for fire wood and, at the same time, as a coop for raising chickens (about 50 fowl). These new conditions allowed the formation of a colony of $T$. dimidiata and in four visits to the place we were able to capture a total of 231 bugs of all stages. Of these insects we examined 137 specimens and found 108 of them infected by Trypanosoma cruzi (78.8\%). We also observed several common rat nests in the place, including some with litters, and after alerting the owners of the need to eliminate the rats, they killed about 30 adults. In this case, the bugs never reached the house and the cellar, with rats and chickens, played a zooprophylactic role (Table I). The stomach contents of 27 specimens from the cellar (one male, six fifth, 11 fourth, six third and three second instars nymphs) were examined by a precipitin test, using antisera against 14 hosts and following the technique of Lorosa et al. (1998). Of these, 21 had rodent blood, either alone (15) or mixed with fowl blood (2), or lizard (2), or opossum (1), or a mixture of rodent, fowl and lizard (1); five had fowl blood either alone or mixed; seven had lizard or lizard and rodent; and two had opossum (one alone and one with lizard). This reinforces the idea that insects in artificial ecotopes, like chicken coops, with plenty of places to hide and abundant blood sources, do not come to the houses to bite humans.

A neighboring chicken coop, with about 35 animals, belonging to another house and separated by only $7 \mathrm{~m}$, was inspected for bugs, but none were found. In this case, the coop was clean with no places for the bugs to hide from chicken predation. A similar situation had been observed before in an urban chicken coop. Nevertheless, if the ecotope includes a store room or dog house in the peridomestic area, some insects may visit the household and feed on humans (Zeledón et al. 2005).
In relation to the 10 control-houses modified a year after the case-houses, we found that in one of them (2A) the inhabitants used the under house space as a store room keeping old items and once more producing the appropriate conditions, for thriving insects. In fact, in two visits to the place we were able to collect 21 specimens of $T$. dimidiata, both nymphs and adults; 18 out of them were examined and three nymphs were infected with $T$. cruzi. In another house (2B) only a death adult bug was found. All remaining houses have maintained the environmental modifications made at the beginning and were free of insects (Table II).

TABLE I

Present condition of the 10 case-houses submitted to ecological control, five years after changes by environmental management in Asserí, San José

\begin{tabular}{|c|c|c|c|c|}
\hline \multirow[b]{2}{*}{ House } & \multirow[b]{2}{*}{ Findings } & \multirow{2}{*}{ 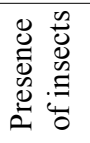 } & \multicolumn{2}{|c|}{ Search time (min) } \\
\hline & & & Indoors & Outdoors \\
\hline 1 & Modifications were kept & No & 30 & 30 \\
\hline $1 \mathrm{~A}$ & Modifications were kept & No & 30 & 35 \\
\hline 12 & Modifications were kept & No & 20 & 30 \\
\hline $13 \mathrm{~A}$ & Modifications were kept & No & 30 & 30 \\
\hline $15 \mathrm{~A}$ & New construction & $\mathrm{No}^{a}$ & 0 & 0 \\
\hline 24 & Modifications were kept & No & 30 & 35 \\
\hline 29 & Modifications were kept & No & 30 & 30 \\
\hline 37 & Modifications were kept & Yes $^{b}$ & 30 & 30 \\
\hline $40 \mathrm{~A}$ & Modifications were kept & No & 30 & 30 \\
\hline 48 & New construction & $\mathrm{No}^{a}$ & 0 & 0 \\
\hline
\end{tabular}

$a$ : the inhabitants have not seen bugs and there are no adequate places for them in the new houses; $b$ : no bugs were found in the modified house but the owners started a chicken coop in the back yard, where 231 insects (Triatoma dimidiata) were found.

\section{TABLE II}

Present condition of the 10 control-houses submitted to ecological control a year later than the 10 case-houses, four years after changes by environmental management in Asserí, San José

\begin{tabular}{|c|c|c|c|c|}
\hline \multirow[b]{2}{*}{ House } & \multirow[b]{2}{*}{ Findings } & \multirow{2}{*}{ 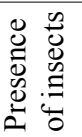 } & \multicolumn{2}{|c|}{ Search time (min) } \\
\hline & & & Indoors & Outdoors \\
\hline 2 & Modifications were kept & No & 30 & 35 \\
\hline $2 \mathrm{~A}$ & $\begin{array}{l}\text { Store room with old } \\
\text { objects again }\end{array}$ & Yes $^{a}$ & 30 & 60 \\
\hline 2B & Modifications were kept & $\mathrm{No}^{b}$ & 30 & 45 \\
\hline 11 & Modifications were kept & No & 30 & 30 \\
\hline 14 & Modifications were kept & No & 20 & 30 \\
\hline $14 \mathrm{~A}$ & Modifications were kept & No & 30 & 30 \\
\hline $16 \mathrm{~A}$ & Modifications were kept & No & 30 & 35 \\
\hline 25 & Modifications were kept & No & 30 & 60 \\
\hline 34 & Modifications were kept & No & 25 & 45 \\
\hline 46 & Modifications were kept & No & 30 & 30 \\
\hline
\end{tabular}

$a$ : in the store room we found 21 specimens of Triatoma dimidiata (nymphs and adults); $b$ : a dead adult was found. 
In conclusion, the environmental modifications consisting of the removal of all T.dimidiata peridomiciliary man-made ecotopes, was shown to be a reliable and sustainable control method after 4-5 years of operation.

The ecological control method not only eliminates all those objects where bugs can hide and thrive, but also destroys the nests of wild or synanthropic animals making it almost impossible for the bugs to live there. Even small nymphs, such as 2nd and 3rd instars, or those originating from remaining eggs, have difficulties in avoiding natural enemies in the clean areas, and newly arriving adults are easily found by predators and do not find an easy source of blood. Several natural predators that tend to limit propagation of $T$. dimidiata are well known (Zeledón 1970).

Although we tested the method against $T$. dimidiata in a pilot project that needs to be extended to larger numbers of infested houses in other places with similar conditions to ours, the method seems appropriate in those cases where the vectors are native to the area, well represented in sylvatic ecotopes, and show a marked tendency to visit and colonize houses. In the case of T. dimidiata, we believe that the method is less costly, more sustainable and more realistic than insecticide spraying as a permanent control procedure. The participation of the communities is important and can be obtained if they are effectively motivated and understand what is being done and what is behind the procedure, as occurred in our case.

Phenetic and genetic studies of different populations of $T$. dimidiata have shown that it behaves as a polytypic species or even represents a complex of cryptic species, suggesting that different control strategies might be needed in certain cases. However, it is also evident that some wild and domestic/peridomestic populations are panmictic, exhibiting similar epidemiological patterns (Dorn et al. 2007, Blandon-Naranjo et al., unpublished observations). These facts makes the application of the ecological control method more viable in different Central American countries, particularly for peridomestic populations of $T$. dimidiata, as part of regular programs for the vectorial control of Chagas disease by the Central American Initiative.

\section{ACKNOWLEDGEMENTS}

To Mr. Carlos Picado, for his field work, to Dra. Francisca Marín, for facilitating valuable information from the last meeting of the Central American Initiative for Chagas Disease Control, and to Dr. Paul Hanson, for reviewing the manuscript.

\section{REFERENCES}

Dorn PL, Monroy C, Curtis A 2007. Triatoma dimidiata (Latreille, 1811): A review of its diversity across its geographic range and the relationship among populations. Inf Gen Evol 7: 343-352.

Lorosa ES, Andrade RE de, Santos SM dos, Pereira CA 1988. Estudo da infeção natural e da fonte alimentar do Triatoma sordida (Stal 1859, Hemiptera-Reduviidae) na região norte de Minas Gerais, Brasil, através da reação de precipitina. Entomol Vect 5: 13-22.

OPS-Organización Panamericana de la Salud 2002. Taller para el Establecimiento de Pautas Técnicas en el Control de Triatoma dimidiata, San Salvador, El Salvador, 11-13 Marzo 2002. OPS/ $\mathrm{HCP} / \mathrm{HCT} / 214 / 02,36 \mathrm{pp}$.

OPS-Organización Panamericana de la Salud 2008. Décima Reunión de la Comisión Intergubernamental de la Iniciativa de los Países de Centro América (IPCA) para la Interrupción de la Transmisión Vectorial, Transfusional y Atención Médica de la Enfermedad de Chagas, Manágua, Nicarágua, 23-30 Agosto 2007, OPS/ $\mathrm{HDM} / \mathrm{CD} / 512 / 08,138 \mathrm{pp}$.

Ponce C 2007. Current situation of Chagas disease in Central America. Mem Inst Oswaldo Cruz 102 (Suppl.I): 41-44.

Zeledón R 1970. Enemies of Triatoma dimidiata Latreille, 1811, in an endemic area of Chagas disease in Costa Rica (Hemiptera, Reduviidae). J Med Entomol 7: 722-724.

Zeledón R 2004. Some historical facts and recent issues related to the presence of Rhodnius prolixus (Stal 1859) (Hemiptera: Reduviidae) in Central America. Entomol Vect 11: 233-246.

Zeledón R, Calvo N, Montenegro VM, Lorosa ES, Arevalo C 2005. A survey on Triatoma dimidiata in an urban area of the province of Heredia, Costa Rica. Mem Inst Oswaldo Cruz 100: 507-512.

Zeledón R, Rojas JC 2006. Environmental management for the control of Triatoma dimidiata (Latreille, 1811), (Hemiptera:Reduviidae) in Costa Rica: a pilot project. Mem Inst Oswaldo Cruz 101: 379-386.

Zeledón R, Ugalde JA, Paniagua LA 2001. Entomological and ecological aspects of six sylvatic species of triatomines (Hemiptera, Reduviidae) from the collection of the National Biodiversity Institute of Costa Rica, Central America. Mem Inst Oswaldo Cruz 96: 757-764. 